\title{
Currículo e Criatividade na Educação Superior
}

\author{
Curriculum and Creativity in Higher Education
}

Joe Garcia ${ }^{1}$

Resumo: Este artigo apresenta uma investigação qualitativa teórica sobre currículo e criatividade na educação superior. A expressiva expansão desse nível de ensino, em diversos países industrializados, originou uma ampla agenda de pesquisas sobre a formação universitária, que englobam diversas questões a indagar, tais como sobre a educação para a criatividade. É nesse contexto que situamos esta investigação, que tem por objetivo analisar um conjunto de princípios para orientar o currículo, tendo em perspectiva sustentar o desenvolvimento da criatividade dos estudantes em cursos de graduação. Nas seções de fundamentação teórica do texto, são exploradas questões sobre criatividade e currículo, bem como o pensamento de teóricos destacados na literatura educacional internacional sobre tais temas. Na parte principal do artigo são apresentados e analisados três princípios teóricos gerais para orientar a elaboração de currículos da graduação, na perspectiva da educação para a criatividade. Eles foram sintetizados de um conjunto recente de investigações teóricas sobre currículo e criatividade na educação superior, com o auxílio de um método de análise qualitativa temática aplicada a um conjunto recente de investigações teóricas sobre currículo e criatividade na educação superior. Os princípios elaborados referem-se tornar o currículo aberto, líquido e inspirado em transdisciplinaridade. Segundo as análises teóricas do artigo, tais proposições trariam mudanças no alcance dos currículos da graduação, na sustentação do desenvolvimento da criatividade dos estudantes.

Palavras-chave: Educação superior. Criatividade. Currículo. 
Abstract: This article presents a qualitative theoretical research on curriculum and creativity in higher education. The significant expansion of this level of education in several industrialized countries has brought about a broad agenda of research on university education, encompassing several questions to ask, such as education for creativity. It is in this context that we situate this research, which aims to analyze a set of principles to guide the curriculum, in order to sustain the development of students' creativity in undergraduate programs. In the theoretical framework sections of the text, questions about creativity and curriculum are explored, based on the international educational literature, as well as the thinking of leading theorists on such topics. In the main part of the article, three general theoretical principles are presented and analyzed to guide the elaboration of undergraduate curricula, from the perspective of creativity education. They were synthesized using a qualitative thematic analysis method applied to a recent set of theoretical research on curriculum and creativity in higher education. The principles refer to making the curriculum open, liquid and inspired by transdisciplinarity. According to the theoretical analysis of the article, such propositions would bring changes in the scope of undergraduate curricula, in support of the development of students' creativity.

Keywords: Higher education. Creativity. Curriculum.

${ }^{1}$ Universidade Tuiuti do Paraná | Programa de Pós-Graduação em Educação | Curitiba | PR | Brasil. Contato: prof_joegarcia@yahoo.com. ORCID: https://orcid.org/0000-0002-4679-020X

- Recebido em: 5 de agosto de 2019

- Aprovado em: 23 de maio de 2021

DOI: http://dx.doi.org/10.1590/S1414-40772021000300003

Este é um artigo publicado em acesso aberto sob uma licença Creative Commons https://creativecommons.org/licenses/by-nc/4.0/ 


\section{Introdução}

Este artigo apresenta uma investigação qualitativa teórica situada no campo dos estudos sobre currículo e criatividade na educação superior. O objetivo é analisar um conjunto de princípios para orientar o currículo, nesse nível de ensino, tendo em perspectiva sustentar o desenvolvimento da criatividade dos estudantes nos cursos de graduação. Para essa finalidade recorremos a um método de análise temática proposto por Thomas e Harden (2008), aplicada a um conjunto de investigações teóricas sobre currículo e criatividade na educação superior, particularmente desenvolvidas nas últimas duas décadas.

A educação superior está em expressiva expansão nos países economicamente desenvolvidos, segundo um relatório de monitoramento da OECD (GLASS, 2014). Esse cenário reflete tanto políticas nacionais de desenvolvimento científico e econômico, quando demandas de diversos setores produtivos. As implicações são diversas, tais como a ampliação de acesso, a flexibilização e a diversificação da oferta de cursos. Mas essa ampliação quantitativa vem acompanhada de diversas preocupações e críticas em relação à qualidade da formação universitária oferecida nas instituições de educação superior. Ela é inegavelmente influenciada por interesses econômicos que exercem diversos tipos de influência que atingem a qualidade dos cursos. Segundo Giroux (2003), há uma tendência histórica na educação para moldar os currículos da educação superior, com base em princípios corporativos e mercadológicos, que além de reorientar os propósitos desse nível de formação, pode restringir o escopo de aprendizagens a serem trabalhadas, bem como o senso de responsabilidade e engajamento social que devem guiar a formação dos estudantes.

O mundo corporativo, que constitui um cenário a considerar na formação dos estudantes na graduação, está pautado por racionalidades que deveriam se vistas com criticidade e nem tanto reproduzidas no pensamento do currículo universitário. A natureza do currículo para a educação da criatividade, na educação superior, não pode considerar apenas os desafios a superar no mundo econômico. O pensamento criativo deve estar aberto a transformar também as lógicas que o atravessam. Além disso, é interessante observar que o mundo corporativo nem sempre solicita a formação de pessoas criativas, sendo que boa parte dos empregos que oferece requer baixa qualificação (GIROUX, 2003).

É nesse cenário que vemos se destacar a importância da criatividade. Se o objetivo da educação superior é formar pessoas segundo o seu melhor potencial, os currículos dos cursos de graduação devem contemplar um conjunto amplo de domínios de desenvolvimento humano, que certamente incluem a criatividade. Atuar em um mundo atravessado por incertezas e grandes desafios econômicos e sociais, certamente requer desembaraço 
intelectual, bem como imaginação e criatividade. A criatividade, assim, precisa ser considerada no currículo, ao lado de habilidades formais de pensamento crítico e reflexivo.

Historicamente, o campo de estudos sobre o currículo tem dedicado mais atenção à criatividade no contexto da educação básica. No entanto, neste momento de expansão da educação superior, seria importante intensificar o debate e as pesquisas sobre a qualidade e outras questões envolvidas nesse nível de ensino. É necessário indagar, por exemplo, se os currículos dos cursos de graduação se encontram desenhados para efetivamente sustentar o desenvolvimento da criatividade dos estudantes. E, se eles ainda precisam avançar nessa direção, quais princípios ou diretrizes gerais poderiam ser considerados? Tal é a questão central deste artigo.

Este artigo está organizado em 3 sessões principais. Inicialmente discutimos o conceito de criatividade, destacando algumas questões teóricas dentre os estudos recentes encontrados na literatura de pesquisa educacional sobre esse tema. Em seguida, analisamos questões sobre criatividade e currículo, explorando o pensamento de um conjunto de teóricos do campo educacional. Então, com base em um método de análise temática, apresentamos um conjunto de princípios que poderiam orientar a elaboração de currículos da graduação, tendo em perspectiva sustentar o desenvolvimento da criatividade dos estudantes. Na última parte do texto apresentamos um conjunto de considerações finais.

\section{A experiência de criatividade}

A criatividade tem sido investigada, há décadas, por diversos teóricos do campo do currículo. Uma parte desse debate refere-se ao papel das artes no currículo, que fornecem diversas linguagens para o desenvolvimento e a expressão da criatividade (FLEMING, 2010; HIRST, 1974; TORRANCE, 1960). Dentre esses teóricos, destacamos Elliot Eisner, por seus diversos estudos sobre imaginação, ensino da arte e a criatividade na formação educacional (EISNER, 1982, 1985, 1986, 1994, 2001, 2003, 2004, 2008a, 2008b, 2017).

Em um estudo publicado ainda nos anos 1960, Eisner argumenta que as artes não deveriam ter a franquia sobre o desenvolvimento da criatividade na escola (EISNER, 1965). Embora valiosas, as linguagens expressivas das artes não podem ser tomadas como as únicas plataformas para o desenvolvimento da criatividade, que se desenvolve também no contexto de todas as outras áreas do conhecimento. Algumas décadas depois, em outro artigo, Eisner argumenta que a criatividade engloba disposições que são difíceis de avaliar, tais como imaginar possibilidades e explorar ambiguidades, manter-se aberto à procura de soluções bem como para reconhecer e aceitar múltiplas perspectivas na resolução de um problema. Embora 
tais disposições sejam complexas e muitas vezes invisíveis aos olhos dos professores, elas podem ser cultivada através de currículos que envolvam diferentes processos de elaboração criativa (EISNER, 1994).

As últimas décadas foram bastante produtivas no campo dos estudos sobre a criatividade no contexto da educação superior. Esse conceito tem se destacado nas políticas educacionais de vários países, para os diversos níveis de ensino, o que parece refletir um entendimento sobre a sua importância na ampla formação humana. Ao mesmo tempo, a literatura de pesquisa sobre criatividade segue afirmando que este é um conceito plural e complexo, mas que ainda estaria em debate e elaboração entre os teóricos (JACKSON, 2006a, KLEIMAN, 2008). Há, no entanto, alguma concordância sobre a criatividade referir-se à elaboração de algo novo ou original que apresenta alguma utilidade para um determinado grupo. Esses dois critérios compõem o que tem sido denominada de definição padrão de criatividade (RUNCO; JAEGER, 2012). No entanto, esse entendimento estaria mais relacionado aos produtos da criatividade que à sua natureza cognitiva.

Morris Stein (1953), um dos primeiros teóricos a propor uma definição formal de criatividade, afirmou que um trabalho criativo deveria apresentar algo novo e aceito como útil por um grupo. Ele ainda sugeriu que a criatividade envolveria um modo de elaboração baseado em uma leitura cultural. Para esse teórico, uma das motivações dos sujeitos criativos estaria relacionada à percepção de lacunas culturais, que seriam reveladas justamente pelas suas elaborações. Stein também analisou alguns possíveis requisitos de uma educação para o desenvolvimento da criatividade, tais como oferecer condições de liberdade de pensamento superando assim uma formação inclinada a gerar conformidade entre os estudantes, já criticada em sua época.

Uma outra leitura conceitual interessante foi apresentada por Kleiman (2008), com base em uma pesquisa realizada com professores universitários. Ele elaborou um conceito de criatividade baseado em cinco possíveis dimensões gerais de experiência. Da mesma for que a criatividade pode ter foco em processos de aprendizagem e na elaboração de produtos, ela poderia ser percebida como experiência de transformação ou modo de auto-realização. Além disso, ela seria uma experiência rica e complexa, mesmo sem ter foco em alguma elaboração. Essa perspectiva apresenta implicações importantes para pensar o currículo na educação superior, pois amplia o entendimento sobre as dimensões ricas e complexas envolvidas na experiência de criatividade. Além disso, essa visão vai solicitar noções mais complexas de currículo, bem como amplia o papel de professores e estudantes na exploração dos diferentes potenciais da experiência de criatividade. 
Embora possamos encontrar, na literatura educacional recente, um entendimento sobre a importância de inserir o desenvolvimento da criatividade dentre as finalidades da educação superior, isso contrasta com a dificuldade para desenhar currículos apropriados, derivada da falta de clareza em relação a questões fundamentais, tais como sobre o próprio conceito de criatividade. Há, na literatura especializada, sobretudo nos campos da Educação e da Psicologia, um conjunto plural de entendimentos sobre a natureza da criatividade, que torna complexo o processo de definir as linhas de um currículo. Essa pluralidade de entendimentos, no entanto, pode ser entendida como valiosa na media em que mantém aberta a exploração de diferentes aspectos da criatividade, bem como estimula a produção de propostas curriculares alternativas para a educação superior. Nesse cenário, nas últimas décadas, a literatura educacional registra diversas experiências formativas ao redor do mundo (SEFTON-GREEN et al., 2011; KAUFMAN; STERNBERG, 2006; STERNBERG, 1999).

Alguns estudos dedicados aos processos cognitivos envolvidos no desenvolvimento da criatividade, no contexto da educação superior, sugerem que eles são influenciados por diversos fatores, tais como o clima de estimulação intelectual, a estrutura institucional e a qualidade dos processos pedagógicos que sustentam o desenvolvimento da criatividade (ALENCAR; FLEITH; PEREIRA, 2017; GARCÊS et al., 2016; SOKOL et al., 2015; ALENCAR; FLEITH, 2010; HUNTER; BEDELL; MUMFORD, 2007). Os processos de construção de conhecimento experimentados pelos estudantes, por exemplo, constituem uma esfera importante de desenvolvimento e expressão da criatividade (BURKSAITIENE, 2018; DONNELLY, 2004). Mas, na base das decisões sobre quais processos serão oferecidos aos estudantes, estão decisões que seguem as diretrizes ou princípios pedagógicos que orientam o currículo. Isso afirma a importância de se investigar possíveis diretrizes curriculares para cursos de graduação dedicados a promover a criatividade.

Na educação superior, o currículo usualmente se baseia em um conjunto de objetivos de aprendizagem, para definir conteúdos, experiências, ambientes, materiais e métodos. Se a criatividade for concebida como elaboração de produtos, por exemplo, os estudantes serão expostos a atividades de aprendizagem nas quais possam explorar diferentes modos de criação. No entanto, o currículo terá outra configuração se a criatividade for entendida como ruptura pessoal com modos anteriores de pensamento. E há outras perspectivas a considerar. Embora uma proposta curricular possa estar baseada em uma noção particular de criatividade, os professores tendem a desenvolver práticas pedagógicas segundo seus próprios modos de compreensão (DONNELLY, 2004). Eles fazem escolhas e mudam o currículo, no contexto 
cotidiano da relação com os alunos. Todo currículo praticado é negociado (SILVA, 1999) e seus detalhes são definidos em processos que envolvem ouvir e integrar as visões dos alunos.

\section{Criatividade e currículo}

A criatividade é um conceito atualmente destacado no campo educacional. No cenário brasileiro, se apresenta no texto de algumas importantes políticas curriculares (BRASIL, 2003, 2018a, 2018b). Esse destaque, no entanto, envolve um certo contraste histórico. Há séculos o currículo das escolas tem sido dominado por uma aspiração tecnicista (EISNER, 2001), que nos legou uma visão restrita de educação e potenciais humanos, mesmo na formação universitária - na qual a principal representação para definir quais os conhecimentos relevantes para compor o currículo tem sido a figura do cientista e não do artista (EISNER, 2005). Essa configuração curricular reflete diferentes razões. De um lado, incidem entendimentos epistemológicos e influências histórico-culturais. De outro, posições ideológicas e demandas do mercado (GIROUX, 2003). Finalmente, embora a criatividade tenha sua importância reconhecida, há muitas interrogações e dúvidas sobre sua natureza e como ela poderia ser efetivamente trabalhada dentro dos contornos do currículo.

O conhecimento que compõe todo currículo resulta de diferentes níveis de seleção cultural (PEDRA, 1993). Segundo Eisner (1982, p. 50) “o currículo envolve escolhas que são representações do modo como concebemos o mundo. No caso dos currículos da graduação, isso não é diferente". Tradicionalmente, eles tendem a privilegiar formas verbais e numéricas de representação do conhecimento, pois seriam supostamente mais importantes para a formação dos estudantes (EISNER, 1982). Esse entendimento, no entanto, atribui um papel secundário à criatividade e resulta na restrição das oportunidades para o seu desenvolvimento. Todo currículo também engloba expectativas de aprendizagem e usualmente requer diferentes formas de adaptação dos estudantes. Sternberg e O'Hara (2000) observaram que os estudantes universitários são capazes de se adaptar às demandas acadêmicas, aprendendo a reproduzir determinados modos de pensamento e adotando condutas que não os ajudam a desenvolver criatividade e servem mais para obter aprovação do que aprendizagem. Com esse comportamento cauteloso, evitam expor ideias criativas, para não arriscar obter críticas ou notas baixas nas disciplinas. Expressar criatividade pode envolver riscos que alguns estudantes preferem evitar.

Mudanças no currículo para sustentar o desenvolvimento da criatividade precisam envolver também inovações nos ambientes de aprendizagem na universidade. Alguns estudos sugerem que o ambiente atua sobre os processos criativos e deveria ser um aspecto melhor 
apreciado na elaboração do currículo (BURKSAITIENE, 2018; LIN, 2011). Seria interessante introduzir espaços onde os estudantes possam explorar a criatividade por meio de jogos e brincadeiras, por exemplo. Isso iria abrir significativamente o alcance e a qualidade da formação na educação superior. Laboratórios de pesquisa são espaços de aprendizagem e elaboração usualmente encontrados na educação superior. Mas, faltam laboratórios de criatividade, para apoiar e ampliar processos de aprendizagem pouco explorados ou mesmo valorizados na universidade. A sala de aula tradicional é um ambiente restritivo para se explorar diversos processos criativos, em que os estudantes possam explorar materiais, tecnologias e experiências incomuns de aprendizagem, criar, modificar e "brincar" com ideias. Nas universidades faltam ambientes para a livre exploração de linguagens e processos que cultivem a criatividade. Faltam espaços se possa inventar, ousar e cometer "erros", combinando e explorando diferentes possibilidades de conhecimento e criação.

Espaços diferenciados, capazes de sustentar atividades e desenvolvimento criativo, podem estar contemplados no currículo, sem ameaçar a formação do pensamento crítico dos estudantes - que usualmente é o foco principal da formação universitária (JACKSON, 2006a). Eles oferecem um suporte pedagógico importante para explorações e aprendizagens abertas, baseadas em experiências sociais relevantes, como os jogos - um recurso usualmente inexplorado ou mesmo desconsiderado na educação superior. Utilizar jogos é uma via particularmente valiosa como ferramenta de criatividade, pois eles envolvem o uso da imaginação em condições abertas de elaboração e decisão. Mas, isso pode trazer mudanças à natureza do currículo, requerer flexibilidade e alguma receptividade à incerteza, o que pode ser algo desafiador, especialmente para os professores.

Finalmente, uma educação voltada à criatividade coloca em questão a natureza padronizada das aprendizagens inseridas no currículo. A prática de estabelecer previamente conteúdos e experiências padronizados, para a formação dos estudantes, contrasta com a tarefa mais complexa de identificar seus talentos e necessidades individuais, de tal forma a oferecer currículos que não ameacem a criatividade (NODDINGS, 2013). É preciso questionar essa abordagem prescritiva que tem dominado a concepção de currículos, até mesmo na educação superior. A criatividade é algo cujo desenvolvimento não pode estar baseado em uma perspectiva de formação fechada, predeterminada e inflexível. As diferentes dimensões da criatividade humana precisam de uma variedade de meios para se expressar e desenvolver. Isso apresenta implicações a considerar na composição do currículo, que precisa integrar diferentes linguagens, espaços e tempos, bem como explorar habilidades que 
oferecem maneiras únicas de representar idéias e sentimentos. Como resultado, teríamos uma formação baseada em um amplo e necessário equilíbrio cognitivo (EISNER, 1982).

\section{Algumas direções para o currículo}

Nesta seção, com base em um método de síntese temática proposto por Thomas e Harden (2008), apresentamos um conjunto de princípios teóricos para o desenvolvimento de currículos na educação superior. Esse método envolve um tipo de análise qualitativa que permite identificar temas, conceitos e entendimentos encontrados dentro de um conjunto de textos de investigações tematicamente relacionadas. É uma abordagem particularmente robusta para estudos baseados na revisão sistemática de literatura de pesquisa. Por meio desse método, inicialmente formamos um corpus de pesquisa, contemplando textos com foco em questões de currículo e criatividade na educação superior (MCINTYRE et al., 2018; ALENCAR; FLEITH; PEREIRA, 2017; BERECZKI, 2016; SEFTON-GREEN et al., 2011; BOVILL; BULLEY; MORSS, 2011; STEILS et al., 2015; KAUFMAN; STERNBERG, 2006; JACKSON, 2006b; BARNETT; COATES, 2005; DONNELY, 2004; KNIGHT, 2011; BARAK; DOPPELT, 2000; TOOHEY, 2000). Em seguida utilizamos o método para elaborar uma síntese teórica, na forma de princípios ou diretrizes gerais para a elaboração de currículos favoráveis ao desenvolvimento da criatividade, em cursos de graduação.

Os textos de pesquisa selecionados são fontes relevantes de referência no campo de estudos sobre criatividade e currículo na educação superior, elaborados por teóricos de diferentes países. Tais fontes se destacaram no exame dessa literatura específica, sendo sistematicamente mencionadas por pesquisadores, bem como por suas contribuições, revisões e sínteses significativas de questões relacionadas ao tema. Tal como sugerem Thomas e Harden (2008), a seleção de materiais para a análise temática tem como critério a localização de estudos que focalizem a questão investigada, sem a necessidade de saturação. Por isso, utilizamos uma estratégia de seleção de fontes usadas em muitas outras formas de investigação qualitativa, baseada em amostragem intencional, pois realizamos uma pesquisa de natureza analítico-interpretativa (DOYLE, 2003). A seguir, apresentamos e analisamos três princípios teóricos gerais, obtidos pelo método em questão. Na descrição de cada um deles encontram-se proposições ao currículo de cursos de graduação, tendo em vista o desenvolvimento da criatividade dos estudantes. 


\section{a) Tornar o currículo "Aberto"}

O currículo é um artefato cultural originalmente criado para guiar professores e alunos no processo de ensino-aprendizagem. É um instrumento que fornece direção às práticas pedagógicas a partir de aprendizagens previamente definidas, que implicam ambientes, materiais e métodos educacionais. O currículo tradicional é um veículo de transmissão e reprodução cultural, refletindo um entendimento de conhecimento válido como aquele fixado previamente segundo critérios formais. Em contraste, um currículo voltado a promover o desenvolvimento da criatividade envolve um certo paradoxo, pois deve conjugar incerteza, abertura ao novo, ao inesperado, a situações e aprendizagens não planejadas previamente.

Os processos cognitivos de representação envolvidos na criatividade são tão fluídos como a conversação (EISNER, 2004). A criatividade envolve modos de elaboração que usam critérios que poderíamos chamar de "abertos", quando comparados às regras de pontuação usadas na escrita, ou na resolução de um problema matemático, por exemplo. Isso faz a educação para a criatividade requerer um currículo com a natureza de um sistema aberto, no qual o trajeto formativo se vai configurando a partir das demandas criativas que se apresentam durante o processo (MORIN, 2011). Essa perspectiva solicita o que Coll (1991) e outros teóricos denominam de currículo aberto.

O conceito de currículo aberto, destacado na literatura educacional, sobretudo a partir dos anos 1970 (WILSON, 1971; ACKOUREY, 1974), fornece uma perspectiva teórica relevante ao nosso tema. Essa proposição afirma que o currículo precisa estar aberto a aprendizagens não planejadas, ou mesmo inesperadas, para melhor sustentar o desenvolvimento da criatividade dos estudantes. Segundo Coll (1991, p. 45), um currículo aberto reconhece as diferenças individuais dos estudantes, bem como é sensível à interação com elementos do seu entorno social, cultural e geográfico. Além disso, ele deve estar aberto a um processo contínuo de redefinição, pelos sujeitos envolvidos.

Segundo Eisner (1985), as práticas educacionais, em diferentes disciplinas do currículo, podem explorar a percepção das qualidades estéticas dos objetos e ideias estudados. Com isso, muitas atividades de sala de aula poderiam proporcionar experiências de criatividade se houver abertura à exploração de linguagens das artes, que oferecem muitas formas de representação para a elaboração de conhecimento e significado (EISNER, 2008b). Um estudo recentemente publicado sobre a inserção de artes visuais no currículo da formação de estudantes de graduação, da área de ciências humanas, observou um impacto positivo na participação e processo de aprendizagem dos estudantes (PUNZALAN, 2018). 
Finalmente, as experiências criativas envolvem descobertas abertas e encorajam respostas únicas e pessoais (EISNER, 1994). Isso se aplica tanto a estudantes quanto a professores na educação superior. Tal como observou Kleiman (2008), a experiência de criatividade envolve muito mais do que elaborar algo criativo. Ela é também uma experiência de percepção, que pode estar inserida no currículo como agente de transformação pessoal e profissional.

A noção de currículo aberto é promissora e complicada. Uma educação baseada em liberdade para elaborar conhecimentos abertos contrasta com a racionalidade dos currículos tradicionais, usualmente sustentados pela noção de conhecimento "objetivo" e "certo", bem como em expectativas predefinidas de aprendizagem que tendem a fixar ou delimitar as realizações dos estudantes. No entanto, embora complicada, a perspectiva de currículo aberto faz sentido e deveria ser considerada em propostas formativas atentas à natureza da criatividade.

\section{b) Tornar o currículo "Líquido"}

Em um mundo de incertezas precisamos de novas visões sociais, novos modos de engajamento e senso de responsabilidade coletiva. Também são necessárias diferentes visões educacionais e proposições alternativas de currículo. Nesse cenário, a educação deve responder a inúmeros desafios e se torna uma prática social particularmente complexa. A tarefa de formar estudantes para um futuro incerto coloca em crise modelos educacionais baseados em antigas racionalidades que supõe a aprendizagem uma experiência delimitável, previsível e prescritível.

Qual a natureza necessária ao currículo, que o torne capaz de proporcionar oportunidades de aprendizagem criativas, significativas e inesperadas, ao longo da formação na graduação? Uma resposta teórica, proposta na literatura educacional, reside no conceito de “currículo líquido". Essa concepção ainda está sendo elaborada por teóricos do campo dos estudos sobre o currículo. É uma proposição que reflete diversas influências conceituais, tais como os escritos de Bauman (2001) sobre a chamada modernidade líquida.

Apenas um currículo líquido consegue se adaptar à complexa e mutável natureza da criatividade experimentada pelos estudantes. Para isso, deve ser uma plataforma capaz se adaptar e englobar as circunstâncias mutáveis requeridas para o desenvolvimento do pensamento criativo. Ele é fluído, no sentido de reconhecer, conjugar e responder a diferentes estilos de pensamento, experiências e interesses dos estudantes, bem como acolher os muitos papeis pedagógicos e modos de envolvimento dos professores. Deve proporcionar 
experiências de aprendizagem que não se encaixam bem em um currículo tradicional, mas que são relevantes para o desenvolvimento da criatividade dos estudantes. Para isso, precisa envolver um diálogo contínuo entre professores e alunos, integrando suas visões, escolhas e disposições, de tal modo a ampliar o escopo de aprendizagens possíveis e significativas, capazes de sustentar o desenvolvimento da criatividade. Para isso, deve levar em conta a constelação de identidades, motivações e estilos de aprendizagem trazidos por eles, que se apresentam e configuram nas muitas formas de criatividade.

Uma noção interessante foi apresentada por Savin-Baden (2008), que o descreve como proposição reflexiva, baseada em emancipação, sensível às disposições e identidades pessoais de alunos e professores, que oferece oportunidades flexíveis e abertas de aprendizagem. Nessa perspectiva, um currículo líquido consegue englobar aprendizagens surgidas em torno de uma constelação de ideias incompletas, intuições, incertezas e impasses, de intenções e possibilidades. Tais aprendizagens líquidas são próprias do pensamento criativo e para englobá-las no currículo, este precisa estar baseado e propor questões que abracem diferentes formas de elaboração criativa, que possam integrar conhecimentos das diversas disciplinas (SAVIN-BADEN, 2008). Com isso, um currículo líquido se constitui uma configuração mutável e fluída de questionamentos e não um conjunto fixado de modos de pensamento e respostas.

Não há na literatura educacional, até o momento, uma concepção única ou estável de currículo líquido. É uma ideia ainda em elaboração, plural e teoricamente complexa, que sugere processos formativos de natureza não linear, flexíveis e adaptáveis aos contextos, circunstâncias e pessoas envolvidas. Ela está relacionada a uma metáfora que descreve a aprendizagem como um fluxo, ao invés de uma cadeia de eventos ou como trajetória fixa baseada em um senso de propósito estável. Em termos gerais, o conceito de currículo líquido está associado às seguintes características principais:

- Ampliação das possibilidades de aprendizagem em condições de incerteza; flexibilização de expectativas de desempenho acadêmico; integração de modos de pensamento não convencional e incorporação de percursos e experiência formativas não previstas ou mesmo imaginadas.

- Abertura a campos de experiências, linguagens e tecnologias que se apresentam nas aprendizagens dos estudantes fora da esfera acadêmica e que podem ser integradas no currículo, tais como envolvendo jogos, modos de conhecimento e interação praticados em redes sociais e outras plataformas digitais. 
- Conjugação da perspectivas e experiências dos alunos sobre criatividade, a fim de considerar e compreender suas necessidades de aprendizagem e o tipo de apoio que precisam para se desenvolver além do ponto em que estão.

Incorporar tais características ao currículo tende a impactar e transformar diversos aspectos das práticas pedagógicas e das condições que as sustentam. Na prática, a noção de currículo líquido implica grandes desafios às universidades. Ao mesmo tempo, explorar essa proposição é algo particularmente necessário nesse nível de ensino - responsável por formar indivíduos para serem flexíveis, inovadores e adaptáveis em um mundo em constante transformação. De um lado, os trajetos formativos deveriam ir além de propostas educacionais construídas em torno de aprendizagens pré-fixadas e modos restritivos de avaliação, que não alcançam a crescente complexidade de conhecimentos e habilidades necessárias para atuar em um mundo pós-industrial. Em complemento, os processos de formação nos cursos de graduação precisam estar mais próximos da dinâmica cambiante de aprendizagem no mundo social, com suas incertezas, mutabilidades e fluxo incessante de reconfigurações.

A implementação de currículos líquidos, segundo Steils et al. (2015), requer uma atuação em parceria, entre professores e estudantes. Todo currículo envolve escolhas e mesmo nesta proposição conceitual há elementos a definir, tais como objetivos de aprendizagem, contextos, materiais, tecnologias, experiências e modos de avaliação. Mas, essa configuração precisa ser elaborada e reelaborada de modo fluído, nos atos de engajamento, diálogo e responsabilidade partilhada entre professores e estudantes. Não se trata, assim, de apenas criar um conjunto de disciplinas flexíveis para serem ensinadas. Um currículo líquido envolve contextos e experiências mutáveis de aprendizagem, que precisam ser propostos e adaptados segundo uma percepção conjunta, em projetos de parceria, que inauguram responsabilidades e papéis colaborativos.

Essa integração de perspectivas mutáveis é importante por várias razões. Ela captura e explora novos entendimentos pedagógicos sobre aprendizagem e criatividade. Abre espaço para motivações, experiências e perspectivas subjetivas dos estudantes, em favor do seu desenvolvimento criativo, bem como para a concepção e uso de ambientes e tecnologias capazes de sustentá-la. Finalmente, também ajuda a democratizar as formas dinâmicas e mutáveis como os processos de ensino-aprendizagem serão pensados, decididos e desenvolvidos ao longo do currículo. 


\section{c) Abrir o currículo à transdisciplinaridade}

Historicamente, a elaboração do currículo tem sido dominada por racionalidades que privilegiam determinados modos e representações do conhecimento, descartando ou reduzindo a importância de outros (SILVA, 1999; EISNER, 1994). Isso reflete a influência de diversos fatores econômicos, sociais e culturais. Tradicionalmente, o currículo é orientado por lógicas de conservação e reprodução cultural, organizado segundo lógicas epistemológicas disciplinares, e voltado ao desenvolvimento do pensamento racional e crítico (JACKSON, 2006a). Embora muito utilizada, essa perspectiva resulta em diversas limitações no desenvolvimento do currículo e consequentemente na formação dos estudantes.

Em sua configuração tradicional, o currículo tem se baseado em objetivos comportamentais de aprendizagem, restritos e predeterminados, para orientar tanto o ensino quanto os modos de avaliação (EISNER, 2005). Essa determinação estreita tem resultado currículos pragmáticos, que focalizam a atenção dos professores naquilo que deve ser ensinado, ao invés de abrir seus olhos a tudo aquilo que os alunos seriam capazes de aprender e criar. Com isso, os estudantes são mais estimulados a reproduzir o que os professores ensinam, que a explorar ideias criativas e complexas que são capazes de elaborar. Esse cenário ainda comum, encontrado na educação superior, precisa mudar. O currículo precisa oferecer abertura para que os estudantes possam experimentar e utilizar diferentes linguagens e modos de pensamento, quando estão aprendendo, explorando recursos e possibilidades que não estejam contemplados nas disciplinas formais que compõe os cursos de graduação.

A criatividade pode ser usada em diferentes formas de aprendizagem, resolução de problemas e elaboração de produtos, por exemplo. Diversos pesquisadores afirmam que não há um processo único de criatividade e que seus processos se distinguem nas áreas do conhecimento (JACKSON, 2006a; KAUFMAN; STERNBERG, 2006; STERNBERG, 1999). Por isso, nos cursos de graduação, deveríamos considerar diferentes possibilidades de estímulo ao desenvolvimento da criatividade. De todo modo, ela constitui um fator fundamental de inovação na educação superior (ALENCAR; FLEITH, 2010; KLEIMAN, 2008), sendo um agente capaz de desafiar os limites das visões, práticas e modos de pensamento estabelecidos nas disciplinas do currículo, e produzir novas perspectivas dentro delas.

Abordagens criativas de produção de conhecimento não raramente envolvem processos cognitivos que articulam elementos de diferentes disciplinas, desafiando e transgredindo fronteiras formais do currículo. A criatividade rompe as fronteiras do currículo de muitas maneiras. Ela não constitui uma experiência humana restrita aos limites e trajetos 
estáveis de pensamento encontrados dentro de uma única disciplina. Ideias criativas podem surgir da exploração de elementos disponíveis em uma ou mais disciplinas, pela exploração de conexões percebidas ou inventadas entre eles. Indivíduos criativos exercem processos cognitivos que originam, transformam, recortam, colam, reposicionam, invertem, duplicam, multiplicam, ampliam e aumentam imagens, formas, ideias, conceitos e todo tipo de elaboração que possa ser usada em processos de criação. Além disso, embora a criatividade explore interpretações e conexões envolvendo as disciplinas, ela está aberta a outras fontes de conhecimento, recorrendo a imagens, objetos, tecnologias e práticas que muitas vezes são desconsideradas pelo currículo oficial, até mesmo por estarem distantes da cultura acadêmica.

As disciplinas comunicam um senso de fronteira, com suas aprendizagens e modos de pensamento, que pode restringir o alcance e a validade das elaborações dos estudantes. Elas veiculam também critérios de reconhecimento e realização. Por isso, sem alguma liberdade criativa, os estudantes podem acabar percorrendo círculos fechados de compreensão, nos quais pensam e produzem as mesmas coisas. Em contraste, os processos de elaboração criativa não raramente tencionam as fronteiras formais das disciplinas do currículo. É claro que os conteúdos, conceitos e teorias, práticas e modos de pensamento que compõe as disciplinas são fundamentais para a formação dos estudantes. Não se trata de deixar de lado as disciplinas e seu papel no currículo. As distinções e especificidades que elas representam são importantes, mas não são suficientes. Por isso, educar para a criatividade precisa envolver liberdade para ir além dos contornos formais dos domínios do conhecimento oficial que compõe o currículo e explorar outras perspectivas culturais de pensamento, eventualmente informais e mais fluídas.

Ao longo da sua formação, os estudantes precisam encontrar no currículo a necessária liberdade de pensamento criativo para explorar, descobrir e conjugar diversas formas de conhecimento e experiência, sem estarem restritos aos limites e racionalidades tradicionais das áreas do conhecimento. Isso deveria incluir a possibilidade de recorrer a saberes culturais encontrados fora das domínios formais do conhecimento acadêmico. Essa perspectiva solicita uma abordagem de elaboração de conhecimento que pode ser encontrada nas teorizações sobre transdisciplinaridade. Esse termo foi originalmente proposto por Jean Piaget, para se referir a um modo ainda incomum, mas complexo, de elaboração de conhecimento, que envolve relações entre diferentes disciplinas, bem como a transgressão dos limites estáveis das suas fronteiras (NICOLESCU, 2010).

Em um estudo que explora diferentes perspectivas de transdisciplinaridade, Klein (2004) distingue duas concepções centrais. Uma delas refere-se à transdisciplinaridade como 
um modo de conhecimento multidimensional, capaz de sustentar formas complexas de diálogo entre diferentes disciplinas, especialistas e níveis de realidade, que torna possível descobrir e criar pontes não somente entre distintas áreas do conhecimento, mas entre instituições e pessoas. Nessa perspectiva, a transdisciplinaridade seria uma visão transcultural, transnacional, que engloba ética, espiritualidade e criatividade. A segunda concepção de transdisciplinaridade a descreve como uma abordagem de pesquisa e resolução de problemas, que abarca saberes de diferentes setores sociais, recorrendo a modos de conhecimento encontrados dentro ou mesmo fora das fronteiras acadêmicas da ciência. Isso amplia radicalmente o campo de elementos culturais e experiências humanas possíveis de serem integrados e considerados dentro do currículo formal. Nessa perspectiva de transdisciplinaridade, a formação universitária se amplia para além da esfera das racionalidades das disciplinas que compõe o chamado conhecimento oficial (APPLE, 1997).

A noção de transdisciplinaridade, em suas diferentes concepções, oferece uma perspectiva interessante tanto para pensar quanto para explorar, em contextos educacionais, o que parece envolvido na experiência de criatividade, que é complexa e plural, não se limitando a determinados setores do conhecimento. A criatividade é um modo de experiência e elaboração aberta a diferentes linguagens, lógicas, conceitos, tecnologias e materiais. É um modo de conhecimento que atravessa fronteiras, podendo combinar múltiplos processos de elaboração e integrar saberes formais e não formais, bem como experiências de diferentes ordens e naturezas. É uma experiência aberta e complexa, capaz de integrar múltiplos níveis de realidade. Assim, há na criatividade uma vocação para a transdisciplinaridade. Seus processos de elaboração e produtos conseguem integrar elementos de diferentes disciplinas acadêmicas, bem como exploram fontes de experiência e linguagem encontrados nos mais diversos setores da cultura. Esse modo de diálogo complexo envolve a construção de pontes entre saberes científicos e a ampla gama de experiências humanas, sem negligenciar setores. A criatividade, assim como a transdisciplinaridade, envolve um modo de elaboração no qual a questão central não reside apenas na solução, mas nas escolhas envolvidas em seu processo (KLEIN, 2004). As duas são tanto formas de ação quanto atitudes. Em ambas encontramos uma disposição para buscar e apreciar, nas muitas dimensões da experiência humana, diferentes modos de conhecimento, linguagem e elaboração.

Sob a perspectiva acima, um currículo para a criatividade deveria ter uma abertura à transdisciplinaridade. Isso se efetivaria, por exemplo, por explorações e elaborações envolvendo a integração de conhecimentos disponíveis em diferentes disciplinas formais, com aqueles encontrados em diversos outros setores da cultura humana. Além disso, a formação 
dos estudantes deveria colocá-los em diálogo e estimular a colaboração com pessoas desses diferentes universos. Finalmente, o currículo deveria explorar os contextos e desafios à criatividade encontrados no campo das práticas profissionais, particularmente, mas não exclusivamente, na área de formação acadêmica dos alunos.

\section{Considerações finais}

Neste artigo apresentamos uma pesquisa teórica tendo ao centro a análise de um conjunto de princípios para pensar o currículo, na educação superior, visando o desenvolvimento da criatividade dos estudantes. A importância da formação para a criatividade é um argumento encontrado em diversos teóricos que têm se dedicado à investigação dos cenários e tendências da educação superior, em diversos países. A questão central explorada neste artigo se integra a esse esforço de pesquisa, indagando, em particular, as configurações necessárias ao currículo para sustentar o desenvolvimento da criatividade.

$\mathrm{Na}$ seção principal do texto apresentamos três princípios teóricos sintetizados de um conjunto recente de investigações sobre currículo e criatividade na educação superior, com o auxílio de um método de análise qualitativa (THOMAS; HARDEN, 2008). Tais proposições fornecem orientações gerais para o desenvolvimento de currículos favoráveis à criatividade dos estudantes. O primeiro princípio sugere tornar o currículo "aberto" a aprendizagens não planejadas, à interação com elementos do entorno social, cultural e geográfico, e a processos de redefinição de conhecimentos e experiências capazes de sustentar a criatividade dos estudantes. O segundo princípio refere-se a tornar o currículo "líquido", seguindo uma metáfora sugestiva da flexibilização dos percursos curriculares, que precisam acolher a incerteza e se adaptar à complexa e mutável natureza da criatividade. Finalmente, o terceiro princípio propõe abrir o currículo à transdisciplinaridade. Tais proposições teóricas envolvem uma expansão radical na natureza dos conhecimentos que poderiam ser trazidos ao currículo dos cursos de graduação, em favor de avanços na formação dos estudantes tendo em perspectiva o desenvolvimento da criatividade.

Estes três princípios contêm proposições teóricas amplas, a serem examinadas em outros estudos dedicados a avaliar suas configurações e impactos na educação superior. Repensar a formação universitária não é uma tarefa simples, pois engloba diversos questionamentos e ponderações sobre os currículos atuais e quais avanços ou rupturas seriam necessários realizar neles. Envolve considerar a natureza das aprendizagens hoje priorizadas e aquelas novas que poderiam ser proporcionadas. Isso faz questionar a própria finalidade da 
educação superior, com suas complexas configurações disciplinares e fragmentações epistemológicas, que inevitavelmente se projetam sobre as propostas curriculares.

A elaboração de currículos envolve várias camadas de seleção cultural e negociação política, sobre as quais atuam forças e interesses, em um processo social complexo - que já foi descrito como uma "conversa complicada" (PINAR, 2004) - para o qual muitos professores talvez ainda precisem se preparar. Não precisamos apenas de novos currículos, mas também aprender a pensar sobre eles de um modo diferente. Esse é um desafio para o qual não podemos supor que todos os professores que atuam na educação superior já estejam preparados. Segundo Moreira (2001), é inadiável a revisão dos currículos da educação superior, mas isso é inseparável da tarefa de aprender a pensar criticamente eles. A elaboração de novas propostas precisa envolver questionamentos sobre conteúdos, métodos de ensino e as condições concretas das práticas docentes em sala de aula. Mas, também é necessário indagar os critérios, os valores, as racionalidade, os interesses e as relações de poder que estão envolvidos nas decisões sobre o currículo. Além disso, as universidades precisam ancorar discussões amplas e suficientemente profundas sobre educação e criatividade.

Os estudos sobre criatividade na educação superior, desenvolvidos nas últimas décadas, revelam avenidas a explorar. A criatividade não se refere apenas a elaborar produtos e encontrar soluções para problemas. É uma atividade humana sem fronteiras utilitárias exclusivas, que pode gerar novas visões sociais e trazer à luz questões ainda não suficientemente percebidas nas diversas esferas da vida cultural. Em um mundo complexo, marcado por tantas incertezas, a criatividade é essencial para a elaboração de novas formas de compreensão, crítica e ação social. Ela é fundamental à educação superior, tanto quanto para a vida no planeta. Precisamos dela para mudar direções, fazer outras escolhas, criar alternativas. Os limites dos nossos modelos e práticas sociais derivam das limitações das nossas racionalidades, tanto quando da falta de criatividade para mudá-las.

\section{Referências}

ACKOUREY, A. The open curriculum: flexibility for better learning. New Directions for Community Colleges, San Francisco, n. 5, p. 1-6, Spring 1974.

ALENCAR, E. S.; FLEITH, D. S.; PEREIRA, N. Creativity in higher education: challenges and facilitating factors. Temas em Psicologia, Ribeirão Preto, v. 25, n. 2, p. 553-561, 2017.

ALENCAR, E. S.; FLEITH, D. S. Criatividade na educação superior: fatores inibidores. Avaliação, Campinas, v. 15, n. 2, p. 201-206, 2010. 
APPLE, M. Conhecimento oficial. Petrópolis: Vozes, 1997.

BARAK, M.; DOPPELT, Y. Using portfolios to enhance creative thinking. Journal of Technology Studies, Blacksburg, v. 26, n. 2, p. 16-25, 2000.

BARNETT, R.; COATES, K. Engaging the curriculum in higher education. Berkshire: Open University Press, 2005.

BAUMAN, Z. Modernidade líquida. Rio de Janeiro: Zahar, 2001.

BERECZKI, E. Mapping creativity in the Hungarian National Core Curriculum. The Curriculum Journal, London, v. 27, n. 3, p. 330-367, 2016.

BOVILL, C.; BULLEY, C.; MORSS, K. Engaging and empowering first-year students through curriculum design. Teaching in Higher Education, London, v. 16, n. 2, p. 197-209, 2011.

BRASIL. Referencial para as Diretrizes Curriculares Nacionais dos Cursos de Graduação. Brasília: MEC, 2003.

BRASIL. Base Nacional Comum Curricular. Brasília: MEC, 2018a.

BRASIL. Diretrizes Curriculares Nacionais para o Ensino Médio. Brasília: MEC, 2018b.

BURKSAITIENE, N. How can university learning environment contribute to students' creativity? Creativity Studies, London, v. 11, n. 1, p. 162-171, 2018.

COLL, C. Psicologia y curriculum. Barcelona: Paidós. 1991.

DONNELLY, R. Fostering of creativity within an imaginative curriculum in higher education. The Curriculum Journal, London, v. 15, n. 2, p. 155-166, 2004.

DOYLE, L. Synthesis through meta-ethnography: paradoxes, enhancements, and possibilities. Qualitative Research, London, v. 3, n. 3, p. 321-344, 2003.

EISNER, E. Children's creativity in art: a study of types. American Educational Research Journal, Washington, v. 2, n. 3, p. 125-136, May 1965.

EISNER, E. Cognition and curriculum: a basis for deciding what to teach. New York: Longmans, 1982.

EISNER, E. The art of educational evaluation. London: Falmer Press, 1985.

EISNER, E. The role of the arts in cognition and curriculum. Journal of Art \& Design Education, Hoboken, v. 5, n. 1-2, p. 57-67, 1986.

EISNER, E. Cognition and curriculum reconsidered. 2. ed. New York: Teachers College Press, 1994.

EISNER, E. The educational imagination: on the design and evaluation of school programs. 3. ed. New York: Pearson, 2001.

EISNER, E. The arts and the creation of mind. Language Arts, Urbana, v. 801, n. 5, p. 340344, May 2003.

EISNER, E. The arts and the creation of mind. 3. ed. New Haven: Yale University Press, 2004.

EISNER, E. Reimagining schools. New York: Routledge, 2005.

EISNER, E. O pode a educação aprender das artes sobre a prática da educação? Currículo sem Fronteiras, Portugal, v. 8, n. 2, p. 5-17, jul./dez. 2008a. Disponível em:

https://www.curriculosemfronteiras.org/vol8iss2articles/eisner.pdf. Acesso em: 10 Jul. 2019. 
EISNER, E. Art and Knowledge. In: KNOWLES, J.; COLE, A. (eds.). Handbook of the arts in qualitative research. Thousand Oaks: Sage, 2008b. p. 3-12.

EISNER, E. The enlightened eye: qualitative inquiry and the enhancement of educational practice. New York: Teachers College Press, 2017.

FLEMING, M. Arts in education and creativity: a literature review. 2. ed. Newcastle:

Creativity, Culture and Education, 2010.

GARCÊS, S. et al. The impact of the creative environment on the creative person, process, and product. Avaliação Psicológica, Campinas, v. 15, n. 2, p. 169-176, 2016.

GIROUX, A. Selling out higher education. Policy Futures in Education, London, v. 1, n. 1, p. 179-200, 2003.

GLASS, A. The state of higher education 2014. Paris: OECD, 2014.

HIRST, P. Knowledge and the curriculum: a collection of philosophers papers. London:

Routlege and Kegan Paul, 1974.

HUNTER, S.; BEDELL, K.; MUMFORD, M. Climate for creativity: a quantitative review.

Creativity Research Journal, London, v. 19, p. 69-90, 2007.

JACKSON, N. (ed.). Developing creativity in higher education: an imaginative curriculum. New York: Routledge, 2006a.

JACKSON, N. Making sense of creativity in higher education. In: JACKSON, N. (ed.). Developing creativity in higher education: an imaginative curriculum. New York: Routledge, 2006b. p. 197-215.

KAUFMAN, J.; STERNBERG, R. (ed.). The international handbook of creativity. Cambridge: Cambridge University Press, 2006.

KLEIMAN, P. Towards transformation: conceptions of creativity in higher education. Innovations in Education and Teaching International, London, v. 3, p. 209-217, 2008.

KLEIN, J. T. Prospects for transdisciplinarity. Futures, Amsterdam, v. 36, p. 515-526, 2004.

KNIGHT, P. Complexity and curriculum: a process approach to curriculum-making.

Teaching in Higher Education, London, v. 6, n. 3, p. 369-381, 2011.

LIN, Y. Fostering creativity through education: a conceptual framework of creative pedagogy. Creative Education, Wuhan, v. 2, n. 3, p. 149-155, 2011.

MCINTYRE, P. et al. Educating for creativity within higher education. London: Palgrave Macmillan, 2018.

MOREIRA, A. F. B. O campo do currículo no Brasil: os anos noventa. Currículo sem Fronteiras, Portugal, v. 1, n. 1, p. 35-49, 2001. Disponível em:

https://www.curriculosemfronteiras.org/vol1iss1articles/moreira.htm . Acesso em: $10 \mathrm{Jul}$. 2019.

MORIN, E. Introdução ao pensamento complexo. Porto Alegre: Sulina, 2011.

NICOLESCU, B. Methodology of transdisciplinarity: levels of reality, logic of the included middle and complexity. Transdisciplinary Journal of Engineering \& Science, Lubbock, v. 1, p. 17-32, 2010.

NODDINGS, N. Standardized curriculum and loss of creativity. Theory Into Practice, New Jersey, v. 52, n. 3, p. 210-215, 2013. 
PEDRA, J. A. Currículo e conhecimento: níveis de seleção do conteúdo. Em Aberto, Brasília, v. 12, n. 58, p. 30-37, abr./jun. 1993.

PINAR, W. What is a curriculum theory? Mahwah: Lawrence Erlbaum, 2004.

PUNZALAN, J. The impact of visual arts in students' academic performance. International Journal of Education and Research, EUA, v. 6, n. 7, p. 121-130, 2018. Disponível em: https://www.ijern.com/journal/2018/July-2018/10.pdf. Acesso em: 10 Jul. 2019.

RUNCO, M.; JAEGER, G. The standard definition of creativity. Creativity Research Journal, Vista, California, v. 24, n. 1, p. 92-96, 2012.

SAVIN-BADEN, M. Learning spaces: creating opportunities for knowledge creation in academic life. New York: McGraw Hill, 2008.

SEFTON-GREEN, J. et al. (ed.). The Routledge international handbook of creative learning. New York: Routledge, 2011.

SILVA, T. T. Documentos de identidade: uma introdução a teoria dos currículos. Belo Horizonte: Autêntica, 1999.

SOKOL, A. et al. Organizational climate of higher education institutions and its implications for the development of creativity. Procedia - Social and Behavioral Sciences, Amsterdam, n. 182 , p. 279-288, 2015.

STEILS, N. et al. Implementing the liquid curriculum: the impact of virtual world learning on higher education. Technology, Pedagogy and Education, London, v. 24, n. 2, p. 155-170, 2015.

STEIN, M. I. Creativity and culture. Journal of Psychology, London, v. 36, n. 2, p. 31-322, 1953.

STERNBERG, R. (ed.). Handbook of creativity. New York: Cambridge University Press, 1999.

STERNBERG, R. J.; O'HARA, L. A. Intelligence and creativity. In: STERNBERG, R. J. (ed.). Handbook of intelligence. New York: Cambridge University Press, 2000. p. 611-630.

THOMAS, J.; HARDEN, A. Methods for the thematic synthesis of qualitative research in systematic reviews. BMC Medical Research Methodology, New York, v. 8, 45, p. 1-10, 2008.

TOOHEY, S. Designing courses for higher education. Buckingham: Open University Press, 2000.

TORRANCE, P. Creative thinking through the language arts. Educational Leadership, Alexandria, v. 18, n. 1, p. 13-18, 1960.

WILSON, L. Open access curriculum. Boston: Allyn and Bacon, 1971. 